\title{
PYROLYSIS OF VARIOUS TYRE TYPES: CHARACTERISTICS AND KINETIC STUDIES USING THERMOGRAVIMETRIC ANALYSIS
}

\author{
Samuel Ayodele Iwarere and Ntandoyenkosi Malusi Mkhize * \\ Discipline of Chemical Engineering, University of KwaZulu-Natal, 238 Mazisi Kunene Road, Glenwood, 4041, South Africa
}

Article Info:
Received:
16 July 2019
Revised:
28 September 2019
Accepted:
04 October 2019
Available online:
20 November 2019
Keywords:
Passenger car tyre
Truck tyre
Pyrolysis
Polyisoprene
Butadiene rubber
Styrene-butadiene rubber

Article Info:

Received:

Revised:

28 September 2019

20 November 2019

Keywords:

Passenger car tyre

Butadiene rubber

Styrene-butadiene rubber

\begin{abstract}
The present study entails investigating the fractional devolatilisation effect on the passenger car tyre (PCT) and truck tyre (TT). Thermograms and their first derivatives are used to profile devolatilisation of the PCT and TT rubbery fractions. Both tyre types rubbery fractions consist of mainly natural rubber (polyisoprene, NR) and synthetic rubber (polybutadiene, BR and styrene-butadiene, SBR). The NR is relatively significant compared to the BR and SBR in the TT. In the PCT, the rubbery fraction showed equal distributions between the NR and BR-SBR. Unlike conventional waste resources pyrolysis processes where the aim is towards energy recovery, novel pyrolysis is designed based on the characteristics of the materials in order to promote the production of the valuable products in addition to the energy recovery. Therefore, kinetic mechanisms pathways of the rubbery fraction devolatilisation from waste tyre pyrolysis are studied and models are developed. Model-free methods, such as Friedman and Kissinger are used to model the kinetics parameters.
\end{abstract}

\section{INTRODUCTION}

Solid waste management has become a global challenge mainly due to improper handling and processing of the end-of-life non-biodegradable materials. It is a common practice to directly dispose of the used materials in the landfills without consideration of the potential value of these materials since they consist of high amounts of carbon and hydrogen. This is mainly due to the lack of stringent environmental regulations and misunderstanding of the economic benefits from the recycling of these materials (Martínez et al., 2013). Both regulations and misinformation are one of the main reasons for the high rate of waste residues piles accumulation in the landfills. It is estimated that 1.5 billion new tyres are sold worldwide each year, while an estimated 4 billion waste tyres are currently reported to be in landfills and stockpiles. Therefore, if unattended to, the disposal of waste tyres will not only become an increasing environmental problem, but also a social and economic issue. It is therefore surprising, that there is the continuous dumping of waste tyres in landfills, which promotes stockpiling. This may result in the creation of breeding grounds for the pests and insects unless there is a substantial investigation of the valorisation of the waste materials, with the thermochemical conversion being one of them.

Among thermochemical processes for waste tyre con- version (Barlaz et al., 1993; Giugliano et al., 1999; Sienkiewicz et al., 2012), pyrolysis is one of the most promising process, since it results in products that have a variety of industrial and domestic applications (Quek \& Balasubramanian, 2013; Williams, 2013). Pyrolysis is defined as the thermal treatment of waste tyres under inert conditions to yield pyro-gas, tyre derived oil (TDO) and pyro-char (Antoniou \& Zabaniotou, 2013; Mui et al., 2004). The pyro-gas can be used as fuel for the endothermic pyrolysis process (Williams, 2013) or various other applications, e.g. when further processed to recover valuable chemicals, such as butadiene or isoprene. TDO's significantly high hydrogen and carbon element content and high concentration of valuable chemicals, e.g., DL-limonene, terpinolene and p-cymene characterise it as a potential alternative for liquid fuel, or as a feedstock for the production of valuable chemicals (Banar et al., 2012; Quek \& Balasubramanian, 2013). The pyro-char mainly contains carbon and can be upgraded into the carbon black or activated carbon (Zabaniotou et al., 2004). However, to achieve these beneficial applications for the waste tyre pyrolysis products, intensive processing to improve products, such as product refining, upgrading, and purification, is required.

Therefore, prior characterisation of the pyrolysis feedstocks is critical since it can reduce or eliminate the processing requirements of the pyrolysis products. Materials characterisation is important in the design or modification
* Corresponding author:

Ntandoyenkosi Malusi Mkhize

email: mkhizen7@ukzn.ac.za 
of the pyrolysis process to target high yield and selectivity of certain chemicals or materials. Most significant tyre fraction which is the main source of volatile matter mainly consists of rubbers, such as natural rubber (polyisoprene, $\mathrm{NR}$ ), butadiene rubber (BR) and styrene-butadiene rubber (SBR) (Williams, 2013). Moreover, the tyre consists of processing additives (fillers, vulcanisation accelerators, inhibitors, etc.), added during tyre compounding (Quek \& Balasubramanian, 2013). It is, therefore, anticipated that kinetic mechanism study models of the pyrolysis of tyres are impossible. This has led to limited literature data on the rubber components characterisation of the waste tyres. Even worse, different rubbery components from different types of waste tyres have not been sufficiently investigated. Various materials characterisation investigations have been conducted using thermogravimetric analysis (TGA) in order to better understand the pyrolysis of a waste tyre (Kim et al., 1995; Conesa et al., 1997; Leung \& Wang, 1999; Mui et al., 2004; Aylón et al., 2005; Mui et al., 2008; Lopez et al., 2009; Cheung et al., 2011; Quek \& Balasubramanian, 2012; Lah et al., 2013; Williams, 2013).

To facilitate the investigation of the tyre rubbery components characterisation, waste tyre devolatilisation needs to be understood (Chen et al., 2001; Friedman, 1964; Kissinger, 1957; Senneca et al., 1999). Kinetics mechanism parameters, such as activation energies (Ea) and pre-exponential rate constants $\left(k_{0}\right)$ in relation to the pyrolysis temperature and heating rate have been reported (Seidelt \& Bockhorn, 2006; Lam et al., 2010; Cheung et al., 2011; Danon et al., 2015). From these studies, a trend illustrating that waste tyre devolatilisation kinetics mainly entails various parallel and serial devolatilisation reaction pathways, such as devolatilisation of the tyre processing oils followed by devolatilisation of the natural rubber and finally synthetic rubbers (SBR and BR). Additionally, waste tyre pyrolysis has been kinetically presented according to products volatilisation, such as gaseous products, variety of TDO sub-fractions (aromatics, aliphatics, polyaromatic hydrocarbons and heteroatom compounds) and char (Olazar et al., 2005).

A multi-stage pyrolysis process with 1) pyrolysis of tyre additives, 2) pyrolysis of polymerised rubbers and 3) pyrolysis of the cross-linked and/or cyclised rubbers (Lam et al., 2010) has been proposed. This study was supported by Cheung et al. (2011) with the following pyrolysis stages: 1) pyrolysis of the volatiles, 2 ) main chain scission (depolymerisation) to intermediates, 3) further depolymerisation of the intermediates (pyrolysis of cross-linked rubbers), and 4) cracking of the intermediates to shorter-chain compounds (degradation) (Cheung et al., 2011). Other authors, Danon et al. (2015), defined tyre rubbers devolatilisation kinetics as a three-stage process: 1) devolatilisation of additives, 2) crosslinking and depolymerisation of the rubbers into intermediates and volatiles, respectively, and 3) finally degradation of the intermediates to volatiles (Danon et al., 2015). Although there seem to be agreements on the observations, however, limited data have been reported on the comparison between the tyre types.

The present work focuses on the kinetic mechanism of two types of waste tyre (truck tyre and passenger car tyre) pyrolysis based on the rubbery fractions devolatilisation. The truck tyre compounding process is different from the passenger car tyre compounding process. Since there is a substantial difference in the tyre compounding process mainly of the rubbery component, characterisation by tracking of the devolatilisation profile of the rubbery fraction of each tyre will reveal this hypothesis. Kinetic mechanism parameters are not merely evaluated for the devolatilisation of the truck tyre rubbery fraction, through the application of thermogravimetric analysis (TGA), but the rubbery fractions are distinctively tracked to evaluate their kinetic mechanism parameters. Moreover, the precise graphical illustration of each rubber component fractions intensifies different stepwise devolatilisation for different types of waste tyres. The heating rate is varied between 10 and $50^{\circ} \mathrm{C} / \mathrm{min}$.

\section{THEORETICAL BACKGROUND}

Kinetic analysis requires tracking of the devolatilisation thermograms of rubbery fractions from waste truck tyres and passenger car tyres. The proposed model is based on the devolatilisation of the NR, BR and SBR. The conversion rate of each rubber fraction is given by the mass fraction devolatilisation equation, Eq. (1).

$\frac{d \alpha}{d t}=k(T) f(\alpha)$

where: $a$ is a mass fraction, $t$ is time, $k(T)$ is reaction rate constant at temperature, $T(K)$, and $f(a)$ is the reaction model.

The time, $t$, and heating rate, $\beta$, can be related by Eq. (2).

$\beta=\frac{d T}{d t}$

where: $\beta$ is the heating rate, and T is the absolute temperature. (3).

The reaction rate constant, k, can be presented by Eq.

$k(T)=k_{0} \exp \left(\frac{-E_{a}}{R T}\right)$

where: $\mathrm{k}$ is the reaction rate constant, $\mathrm{k}_{0}$ is a pre-reaction rate constant, $E_{a}$ is the activation energy, and $R$ is the universal gas constant.

Therefore, by substituting Eq. (2) and Eq. (3) in Eq. (1): $\frac{d \alpha}{d T}=\frac{1}{\beta} k_{0} \exp \left(-\frac{E_{a}}{R T}\right) f(\alpha)$

\subsection{Determination of kinetic parameters}

Kinetic parameters $\left(E_{a}\right.$ and $k_{0}$ ) are determined using various techniques classified according to i) pyrolysis conditions, i.e., isothermal or non-isothermal, or ii) mathematical analysis of the experimental results, i.e., linear or nonlinear. In the current study, non-isothermal pyrolysis conditions were used since the experiments were carried out at various heating rates $\left(10,20,30,40\right.$ and $\left.50^{\circ} \mathrm{C} / \mathrm{min}\right)$. The linear mathematical analysis methods for experimental results analysis were selected due to their conventional application in the analysis of thermal devolatilisation of the solids. These methods allow the determination of a linear relationship between the kinetic parameters using 
mass loss data generated at various devolatilisation rates. Linear regression methods using experimental results are applied to determine coefficients of the linear relation. Typical non-isothermal and linear methods were considered in the present study, in particular, the iso-conversional methods of Friedman (differential approach) and Kissinger (integration approach) (Friedman, 1964; Kissinger, 1957). The mathematical methods were used in the analysis of the experimental results.

\subsection{Friedman method}

Taking a natural logarithm of Eq. (4), the linear relationship is employed in the equation and resulted in Eq. (5).

$\ln \left(\beta \frac{d \alpha}{d T}\right)=\ln k_{0}+\ln f(\alpha)-\frac{E_{a}}{R T}$

Plotting $\ln \left(\beta \frac{\mathrm{d} \alpha}{\mathrm{dT}}\right)$ versus $\frac{1}{\mathrm{~T}}$ at given reaction progress, $a$, for various heating rates yields a straight line with slope $\frac{-E_{a}}{2}$. Activation energy can be obtained from this slope without knowing the reaction function $f(a)$. The preexponential reaction rate constant, $k_{0}$, is the $y$-intercept of a straight line. Friedman method is one of the model-free iso-conversional method (Friedman, 1964).

\subsection{Kissinger method}

The Kissinger method is based on the determination of the temperature at the maximum devolatilisation rate of the rubber fractions (NR, BR or SBR), at various heating rates (Kissinger, 1957). In the Kissinger method, Eq. 4 is modified to Eq. (6).

$\ln \left(\frac{\beta}{T^{2}}\right)=\ln \left(\frac{k_{0} R}{f(\alpha)}\right)-\frac{E_{a}}{R T}$

A plot of $\ln \left(\frac{\beta}{T_{\max }^{2}}\right)$ versus $\frac{1}{T_{\max }}$ at various heating rates yields a straight line that allows for the determination of the activation energy, $E_{a^{\prime}}$ from the gradient of the straight line, $\frac{-E_{a}}{R}$. The $y$-intercept can be used to estimate the preexponential reaction rate factor. Similar to the Friedman method, Kissinger method is another example of a modelfree iso-conversional method.

\section{EQUIPMENT AND METHOD}

TT and PCT crumbs (steel- and fabric-free) samples with the particle size range of 0.6 to $0.8 \mathrm{~mm}$ were obtained from the local waste tyre recycler. A slightly adjusted version of ASTM E1131-08 (with $X=275^{\circ} \mathrm{C}$ ) was used to determine proximate analysis. Additionally, the rubber composition of the crumb was determined using a procedure described by (Danon \& Gorgens, 2015). The results of the proximate and elemental analysis are shown in Table 1.

The proximate analysing was done using the TGA which was carried out on both tyre types TT and PCT. To determine the mass loss as temperature increases, the maximum temperature was set to $800^{\circ} \mathrm{C}$, nitrogen $\left(\mathrm{N}_{2}\right)$ and oxygen (02) were used as a carrier gas to trace devolatilisation profile and to determine ash content, respectively. A TA 60WS model TGA (Shimadzu ${ }^{\mathrm{TM}}$, Kyoto, Japan) was used for all the experiments. The calculations were done using the Standard Test Method for Compositional Analysis by Thermogravimetry, designation: ASTM E 1131-08, (2008).
All the experiments were conducted in duplicates to ensure the repeatability of the results.

\section{RESULTS AND DISCUSSION}

\subsection{Thermogravimetric analysis}

Shown in Figure 1 is the solid residual for truck tyre and passenger car tyre. The reported char values are the average estimated from all the heating rates $\left(10\right.$ to $50^{\circ} \mathrm{C} /$ $\mathrm{min}$ ). From the thermogravimetry (TG) profiles in Figure 1 it can be observed that, regardless of the heating rate, the profiles converge at the same value of solid residual at the end of the pyrolysis TG. This indicates that the heating rate effect on the mass and energy transfer is relatively insignificant and can be ignored in the analysis of the present study. Moreover, the observed char residuals, $36.2 \mathrm{wt}$. \% for TT and similarly, the PCT at $36.2 \mathrm{wt}$ \% (Table 2), is comparable to the previously reported work (Mkhize et al., 2016). This is not surprising since the fixed carbon mainly in the form of the carbon black added to the tyre compounding is likely to be the same for both the TT and the PCT. Therefore, the next step is the characterisation of the volatile matter, mainly rubber fraction of the two tyre types.

TT and PCT first derivative thermogravimetric (DTG) and reaction progress profiles on the pyrolysis temperature basis at various heating are illustrated in Figure 2. The shape of the curves of the TT is significantly different from that of the PCT. The observed distinction between the devolatilisation profiles for the two tyre types is critical, considering that the compounding process between the two tyre types is relatively different. Therefore, in order to relate the tyre compounding process, devolatilisation profile peaks from the two tyre types are analysed. Two distinctive peaks are observed in the PCT, mainly at higher heating rates, whereas, in the TT profile only one peak was observed and became firmly one peak at higher heating rates. This can, therefore, be attributed to the fraction composition difference of the rubber fractions from each tyre type. From previous investigations, it has been reported that TT rubber fraction mainly consists of natural rubber, while in the PCT, the rubber fraction is equally distributed between the NR and synthetic rubber (butadiene, BR, or styrene-butadiene, SBR). The equal distribution between the two rubber types in the PCT is supported by the identical peaks shown in Figure 2, particularly at a heating rate of $50^{\circ} \mathrm{C} / \mathrm{min}$. In the wake of new interests in the production of valuable products in addition to the energy recovery, the design of the pyrolysis system is depended on the characteristics of the feedstock. For example, the two distinguishable peaks, indicating maximum devolatilisation rate within a wide range of temperature (around $100^{\circ} \mathrm{C}$ different), is an indication of the potential of step-wise temperature devolatilisation of rubber fractions. As for the TT, the shape of the curves at a lower heating rate show two peaks, i.e. the main devolatilisation peak at low temperature and a small peak (shoulder) at the high temperature. The shoulder (relative small additional peak compared to the main large peak) on the high-temperature side of the peak disappears as the heating rate increases. In the earlier studies (Danon et al., 2015), this has been attributed to the elimination of the 
secondary reactions (primary products cracking) at higher heating rates, while promoting devolatilisation of the rubbers. Moreover, as observed in the previous studies, the effect of the heating rate on the devolatilisation peak temperature is characterised by an increase in the temperature associated with the maximum devolatilisation rate (in both the TT and PCT) as the heating rate increases.

\subsection{Reaction Progress}

The reaction progress of both the TT and PCT is illustrated in Figure 2. The reaction progress profile of the TT matches that of the PCT. However, at a refined view, the gradient of the profile is steeper for the TT as compared to the PCT. The low rate of the devolatilisation of the PCT (i.e., less steep gradient in the PCT is attributed to the two peaks as observed from the derivative thermogravimetric profiles. This also indicates not only the delay in the devolatilisation of the PCT compared to the TT but sufficient time for fractional devolatilisation of the rubber fractions. In order to show a better illustration of the fractional devolatilisation, the plots of the different tyre types activation energy, $\mathrm{E}_{\mathrm{a}}$ as a function of time are critically analysed.

\subsection{Friedman method}

Figure 3 illustrates the estimated values of the TT and PCT linear plots, apparent activation energy, $E_{a^{\prime}}$ and preexponential factor $\mathrm{k}_{0}$, as a function of reaction conversion with the differential-based, iso-conversional Friedman method. The linear plots of the TT have an identical gradient (from a plot of $\ln \left(\beta \frac{\mathrm{d} \alpha}{\mathrm{dT}}\right)$ versus $\frac{1}{T}$ ) as illustrated in Eq. 5. In other words, the activation energy $\left(E_{a}\right)$ is independent of the reaction progress, therefore, a constant $E_{a}$ with the progress of devolatilisation.

The linear plots for PCT differ from that of the TT in
TABLE 1: Proximate and elemental analysis of truck tyre and passenger car tyre.

\begin{tabular}{l|cccccc}
\multicolumn{2}{l}{ Proximate analysis (wt. \%) } & & & \\
\hline Tyre type & Moisture & Oils & $\begin{array}{c}\text { Volatile } \\
\text { matter }\end{array}$ & $\begin{array}{c}\text { Fixed } \\
\text { carbon }\end{array}$ & Ash \\
\hline TT & 0.6 & 5.6 & 56.0 & 30.0 & 7.8 \\
\hdashline PCT & 0.6 & 5.4 & 55.9 & 29.9 & 8.2 \\
\hline Elemental analysis (wt. \%) & & & & \\
\hline Tyre type & Carbon & Hydrogen & Sulphur & Nitrogen \& Oxygen \\
\hline TT & 81.1 & 7.4 & 1.9 & \multicolumn{2}{c}{9.7} \\
\hdashline PCT & 79.3 & 7.5 & 1.2 & \multicolumn{2}{c}{12.0} \\
\hline
\end{tabular}

a By difference

that there are two sets of the linear plots, i.e., the first set from reaction progress of 0.1 to 0.5 and the second set from reaction progress of 0.5 to 0.9 . Each of these sets has a maximum peak at different reaction progress, i.e., maximum $\mathrm{E}_{\mathrm{a}}$ at reaction progress of 0.4 and 0.8 , respectively. Alternatively, the peak dependence on the reaction progress is expressed in $\mathrm{E}_{\mathrm{a}}$ and/or $\mathrm{k}_{0}$.

The TT activation energy $\left(E_{a}\right)$ as a function of the reaction progress has a form of the peak with the maximum value at a reaction progress 0.7 . For the rest of the reaction progress, the $\mathrm{E}_{\mathrm{a}}$ remained relatively constant at approximately $166.3 \mathrm{~kJ} / \mathrm{mole}$. The $\mathrm{E}_{\mathrm{a}}$ for PCT was estimated at 177.4 $\mathrm{kJ} / \mathrm{mole}$, slightly higher than that of the TT. The higher $\mathrm{E}_{\mathrm{a}}$ for PCT compared to TT reflects a slight difference in the polymer composition. This can be attributed to the significant amount of NR in the PCT compared to the TT content of the BR and SBR. Therefore, the minimum energy required to devolatilise each NR, BR or SBR fraction differs. Such difference in the $E_{a}$ may suggest and be supportive of the

TABLE 2: Kinetic parameters estimated using iso-conversional methods for PCT and TT.

\begin{tabular}{|c|c|c|c|c|c|}
\hline \multirow[t]{2}{*}{ Parameter } & & \multirow[t]{2}{*}{ TT } & \multirow[t]{2}{*}{ РCT } & \multicolumn{2}{|c|}{ РCT } \\
\hline & & & & PCT peak 1 & РCT peak 2 \\
\hline Residue char (wt. \%) & & 36.2 & 36.2 & & \\
\hline \multirow{2}{*}{$\mathrm{E}_{\mathrm{a}}\left(\mathrm{kJ} . \mathrm{kmol}^{-1}\right)$} & Friedman & 166.3 & 177.4 & 131.7 & 139.4 \\
\hline & Kissinger & 128.5 & 177.7 & 136.1 & 165.0 \\
\hline \multirow{2}{*}{$\mathrm{k}_{0}\left(\mathrm{~s}^{-1}\right)$} & Friedman & $1.97 \times 10^{12}$ & $1.04 \times 10^{13}$ & $4.01 \times 10^{8}$ & $4.92 \times 10^{7}$ \\
\hline & Kissinger & $4.20 \times 10^{8}$ & $8.91 \times 10^{10}$ & $1.48 \times 10^{9}$ & $1.22 \times 10^{10}$ \\
\hline
\end{tabular}
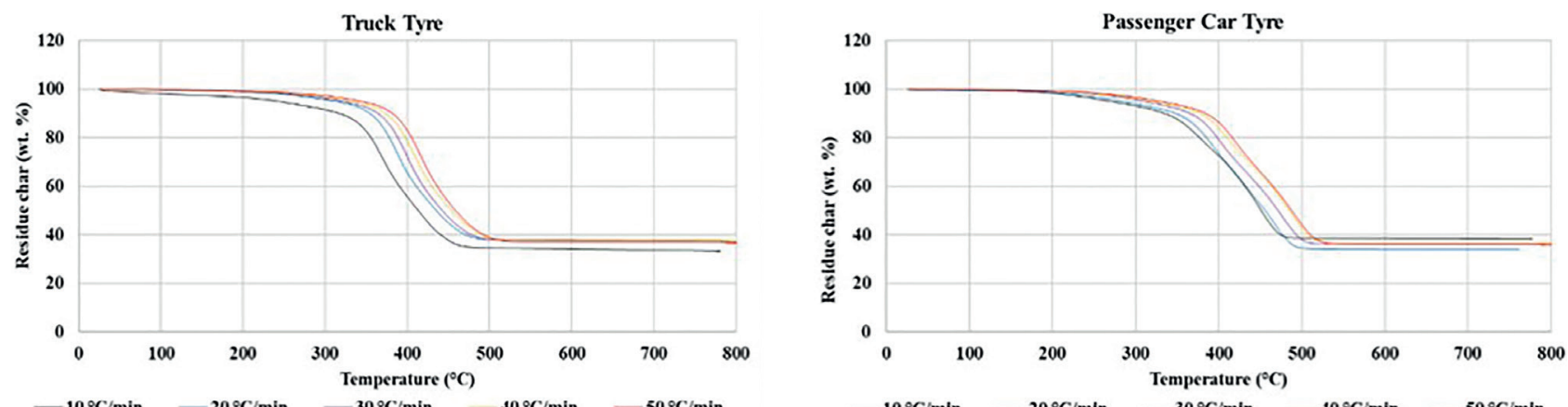

FIGURE 1: Percent devolatilisation of the various waste tyres showing residual char. 

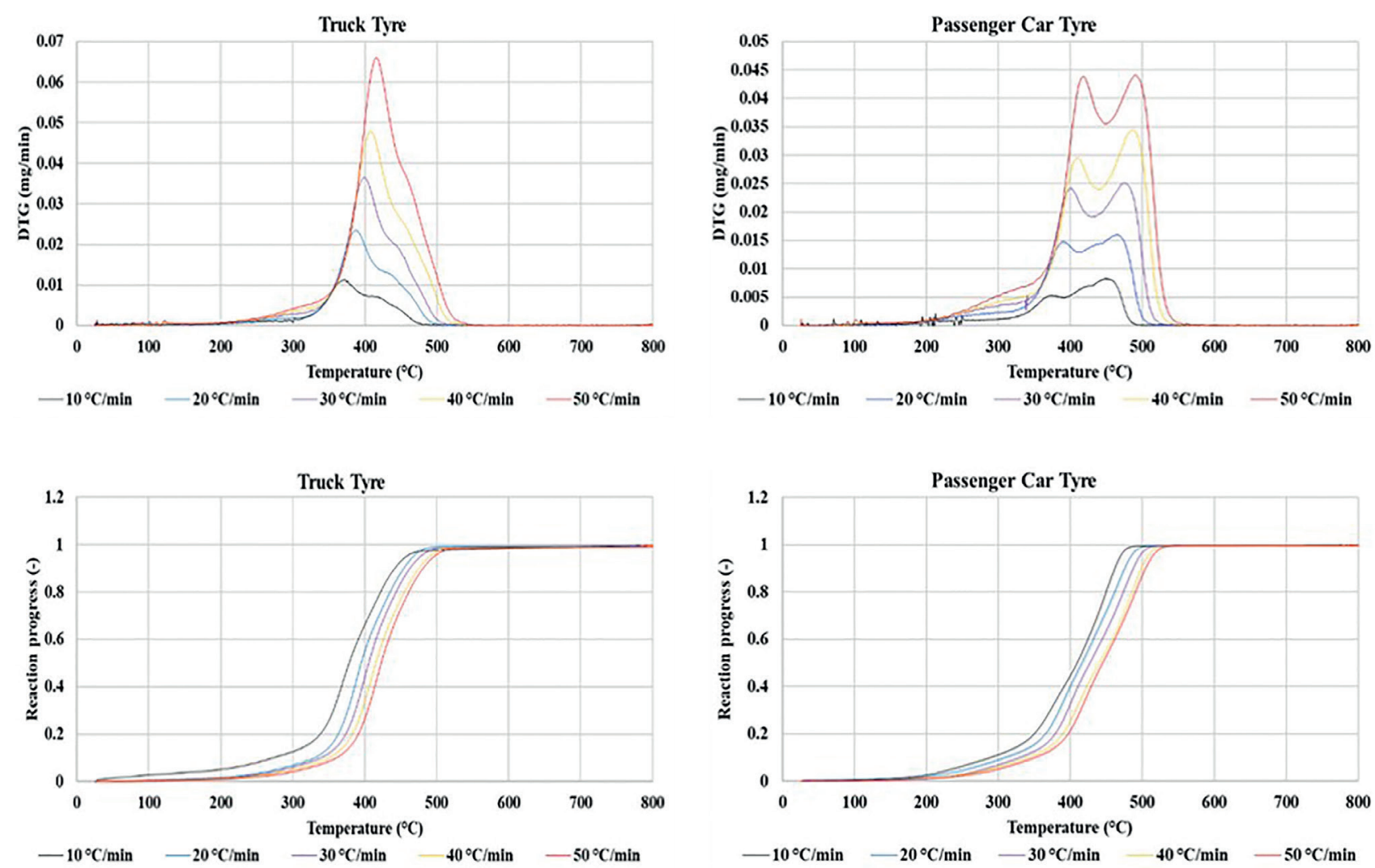

FIGURE 2: Profiles of the derivative thermogravimetric (DTG) and reaction progress of the waste truck tyre.

proposal of stepwise pyrolysis or selective devolatilisation of the rubbery components of the tyres. Typical ratios of NR to synthetic rubber (SBR and BR) are 2:1 and 4:3 for TT and PCT, respectively (Mui et al., 2004). Lopez et al. (2009) reported that the composition of a waste tyre was $60 \mathrm{wt}$. \% rubber, of which NR and SBR were 29.95 and 29.95 wt. \%, respectively (Lopez et al., 2009). Waste tyre crumb used in their investigation was steel and fabric free PCT. However, the rubber ratio was not reported. Another study conducted by the same group used TT waste tyre consisting of 58.89 wt. \% NR representing the entire rubber content of the waste tyre (Lopez et al., 2009). The rubber composition of the waste tyre reported by Danon and Görgens (2015) was 64 wt. \% NR and 36 wt. \% synthetic rubber (SBR and BR) (Danon \& Gorgens, 2015).

Finally, the pre-exponential factor, $\mathrm{k}_{0}$ is reported in $\mathrm{Fi}$ gure 3. A similar trend as in the $\mathrm{E}_{\mathrm{a}}$ on both the TT and PCT tyre types are observed with the $k_{0}$. The average $k_{0}$ for the TT was estimated at $1.97 \times 10^{12}$, while for PCT it was estimated at $4.20 \times 10^{8}$. If the definition of the frequency of molecules collision is adopted, it means that for the TT, the frequency of the molecules is significantly higher than the frequency of the PCT. Also, to be noted is the peaks at certain reaction progress, i.e., at 0.7 for TT and 0.4 and 0.8 for PCT, were observed. This is an indication that the kinetic parameters suggest that TT devolatilisation is one step, while PCT volatilization is a two-step process.

\subsection{Kissinger method}

The Kissinger method as an iso-conversional method provides an alternative to Friedman method. It is based on an integration approach and can be used to estimate $E_{a}$ for both TT and PCT devolatilisation. The Kissinger plots for TT and PCT are shown in Figure 4. Using the Kissinger method plots, the $\mathrm{E}_{\mathrm{a}}$ for TT was estimated at $128.5 \mathrm{~kJ} /$ mole while for PCT was at $177.7 \mathrm{~kJ} / \mathrm{mole}$. A significant difference between the $\mathrm{E}_{\mathrm{a}}$ from the Friedman method and the Kissinger method has been observed in the TT at around $38 \mathrm{~kJ} / \mathrm{mole}$, whereas for PCT the difference was insignificant (around $0 \mathrm{~kJ} / \mathrm{mole}$ ). This was expected since the TT peak has the shoulder which disappears as the heating rate is increased, i.e., the shoulder is absorbed to the main peak which affects the estimation of the $E_{a}$. In the PCT profile, the two distinguishable peaks from the devolatilisation allowed separation of the different tyre rubber fractions as well as estimation of the $E_{a}$. This is also due to the fact that the two peaks from the PCT are almost identical and well separated.

An overlay of the TT and PCT derivative thermogravimetric profiles is illustrated in Figure 5. Since identical rubber components are likely to behave similarly under thermal devolatilisation regardless of the tyre type of origin, this constitutes an acceptable standard to associates kinetic parameters $\mathrm{E}_{\mathrm{a}}$ and $\mathrm{k}_{0}$ with the propose rubber component from the different tyre types. The PCT first peak corresponds to the TT main peak, while the second PCT peak corresponds to the shoulder of the TT main peak. As the heating rate is increased, both the TT main peak and PCT first peak's maximum devolatilisation temperature increases. Complete disappearance of the TT shoulder allows a 

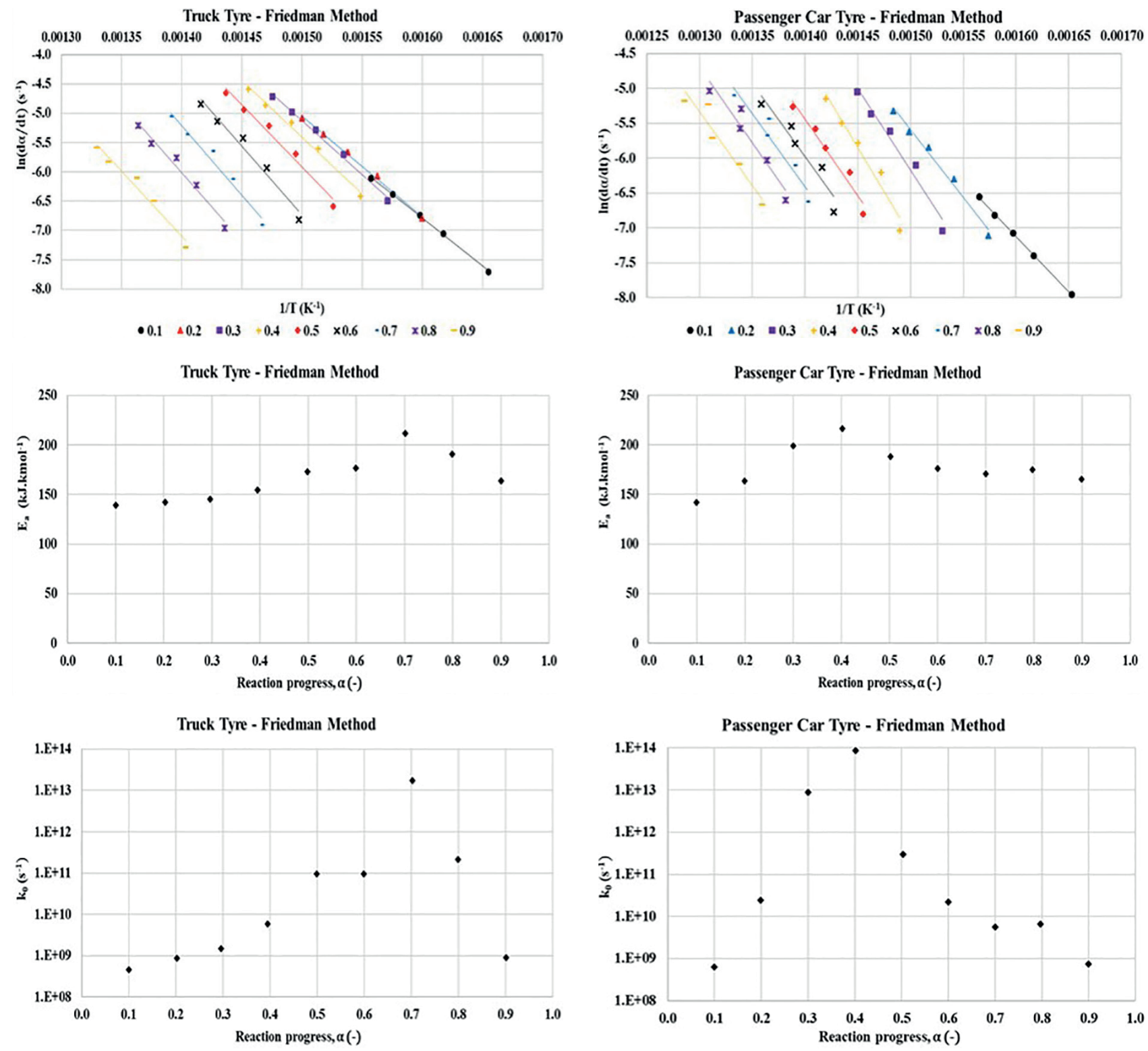

FIGURE 3: Iso-conversional Friedman method linear plots, activation energy, $\mathrm{E}_{\mathrm{a}^{\prime}}$ and pre-exponential reaction constant.


FIGURE 4: Iso-conversional Kissinger method plot for truck tyre and passenger car tyre at various reaction progress.

better illustration of the second peak from the PCT. Overall, the intensity of the TT peaks (except the shoulder) is higher than that of the PCT peaks. This can be attributed to the difference in the volatility of the rubber fractions of these types of tyres. 


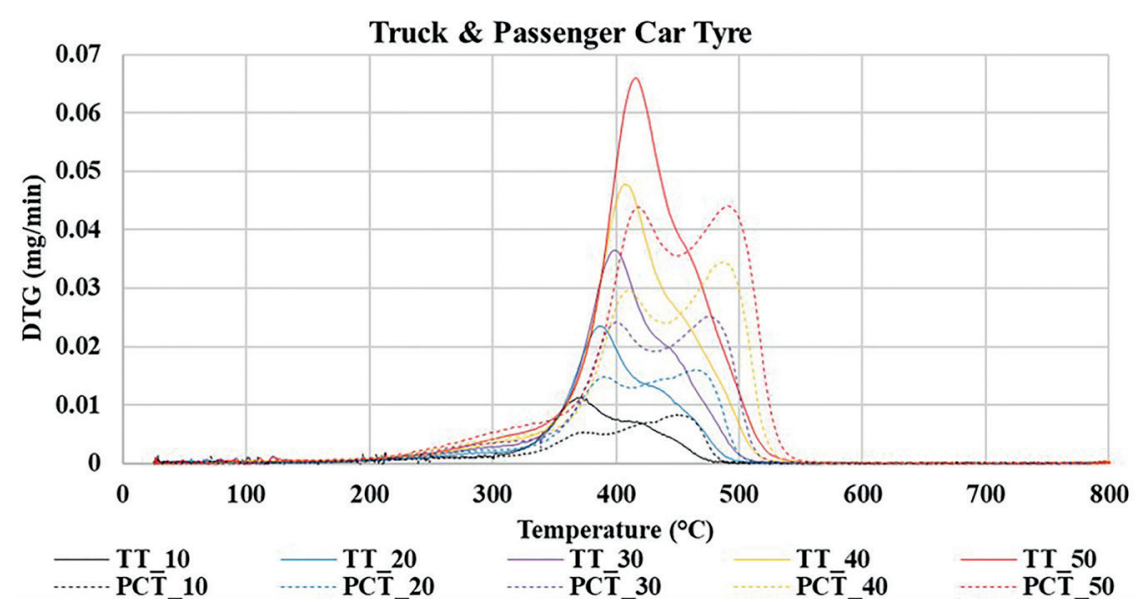

FIGURE 5: Overlay profiles of the derivative thermogravimetric (DTG) waste truck tyre and passenger car tyre.

\subsection{Fractional devolatilisation of the PCT}

An overlook of the potential of fractional devolatilisation of the PCT rubber is interesting since relatively two distinctive peaks were observed. Figure 6 shows the PCT fractional derivative thermograms and iso-conversional Friedman method analytical plots. It should be noted that in the ideal state, the two peaks have some effect on each other. However, for concept illustration purposes, the interaction effects of the peaks may be relatively less when compared to the potential benefits, such as product selective devolatilisation of heterogeneous materials.

The two distinctive peaks for PCT devolatilisation can easily be illustrated as two different plots. This implies that the two peaks can be model separately as was shown and illustrated by Danon and Görgens (2015). A significant improvement in the $E_{a}$ as a function of a plots was observed when the PCT peaks were separately analysed or modelled, see Figures 3 and 6 . The $E_{a}$ versus a plots are better and consistent, each with a single peak shaped distribution. The average $E_{a}$ was estimated at $131.7 \mathrm{~kJ} / \mathrm{mole}$ on the peak 1 while the second peak 2 was estimated at $139 \mathrm{~kJ} /$ mole. The $\mathrm{E}_{\mathrm{a}}$ for peak 2 is higher than that of peak 1 by 7.7 $\mathrm{kJ} / \mathrm{mole}$ indicating a potential for the step-wise pyrolysis of the PCT. This can also be used as a basis for fractional recovery of the valuable products from waste tyre valorisation, most particularly as an indication that slightly more energy is required to devolatilize BR/SBR fraction. The parameter $\mathrm{k}_{0}$ was at $4.01 \times 10^{8}$ and $4.92 \times 10^{7}$ for peak 1 and peak 2 , respectively.

A similar trend on both the $E_{a}$ and the $k_{0}$ was observed with the Kissinger method. The $\mathrm{E}_{\mathrm{a}}$ for peak 1 and peak 2 were 136.1 and $165.0 \mathrm{~kJ} / \mathrm{mole}$, respectively. The difference between the $E_{a}$ of peak 1 and that of peak 2 using the Kissinger method is substantial at $28.9 \mathrm{~kJ} / \mathrm{mole}$ compared to the one from Friedman method. This may be a good support for the fractional pyrolysis of the PCT. However, the difference between the $\mathrm{E}_{\mathrm{a}}$ from Friedman method and Kissinger method is quite significant at $25.5 \mathrm{~kJ} / \mathrm{mole}$. The $\mathrm{k}_{0}$ is also comparable with the Friedman method generated value, i.e., for peak $1, \mathrm{k}_{0}$ of $4.01 \times 10^{8}$ and $1.48 \times 10^{9}$ were obtained from Friedman method and Kissinger method, respectively. Figure 6 shows the Kissinger method iso-conversional method for peaks 1 and $2 \mathrm{E}_{\mathrm{a}}$ estimation. The parameters for both the TT and PCT are illustrated in Table 2.

\section{CONCLUSIONS}

The increase in the heating rate up to $50^{\circ} \mathrm{C} / \mathrm{min}$ increased the peak temperature of both the TT and PCT maximum devolatilisation temperature. The TT devolatilisation is characterised by one main fraction of the tyre rubber, which when the devolatilisation heating rate is increased, the peak shoulder disappears. The main peak from the TT profile was attributed to the natural rubber, the main rubbery fraction of the TT. Two distinctive peaks were observed in the devolatilisation of the PCT, peak 1 was sought to be the natural rubber (or polyisoprene), whereas peak 2 was associated with synthetic rubber (i.e., BR and SBR). The observation may suggest that there is a high potential for stepwise pyrolysis of the fractions from the tyre rubber, particularly PCT. The step-wise pyrolysis of the PCT is more favourable at a higher heating rate since the separation between two distinctive peaks is significant. Selective pyrolysis of the tyre rubbers may be beneficial to the recovery of the valuable chemicals from the waste tyre or other rubbery materials. The difference in the kinetic parameters of the components of the waste tyre rubbery fraction substantiates the difference in the reaction pathways. Therefore, waste tyre pyrolysis reactor design proposal should consider the distinctive behaviour of various rubbery fraction in the tyres during thermochemical devolatilisation of waste tyres. Moreover, since various rubber components devolatilisation was observed, the mirror various products can be observed and targeted for recovery.

\section{ACKNOWLEDGEMENTS}

This research was in part supported by the University Capacity Development Grant (UCDP) of The Department of Higher Education (DHET). The authors acknowledge that opinions, findings and conclusions or recommendations expressed are those of the authors only, and the sponsors accept no liability whatsoever in this regard. 

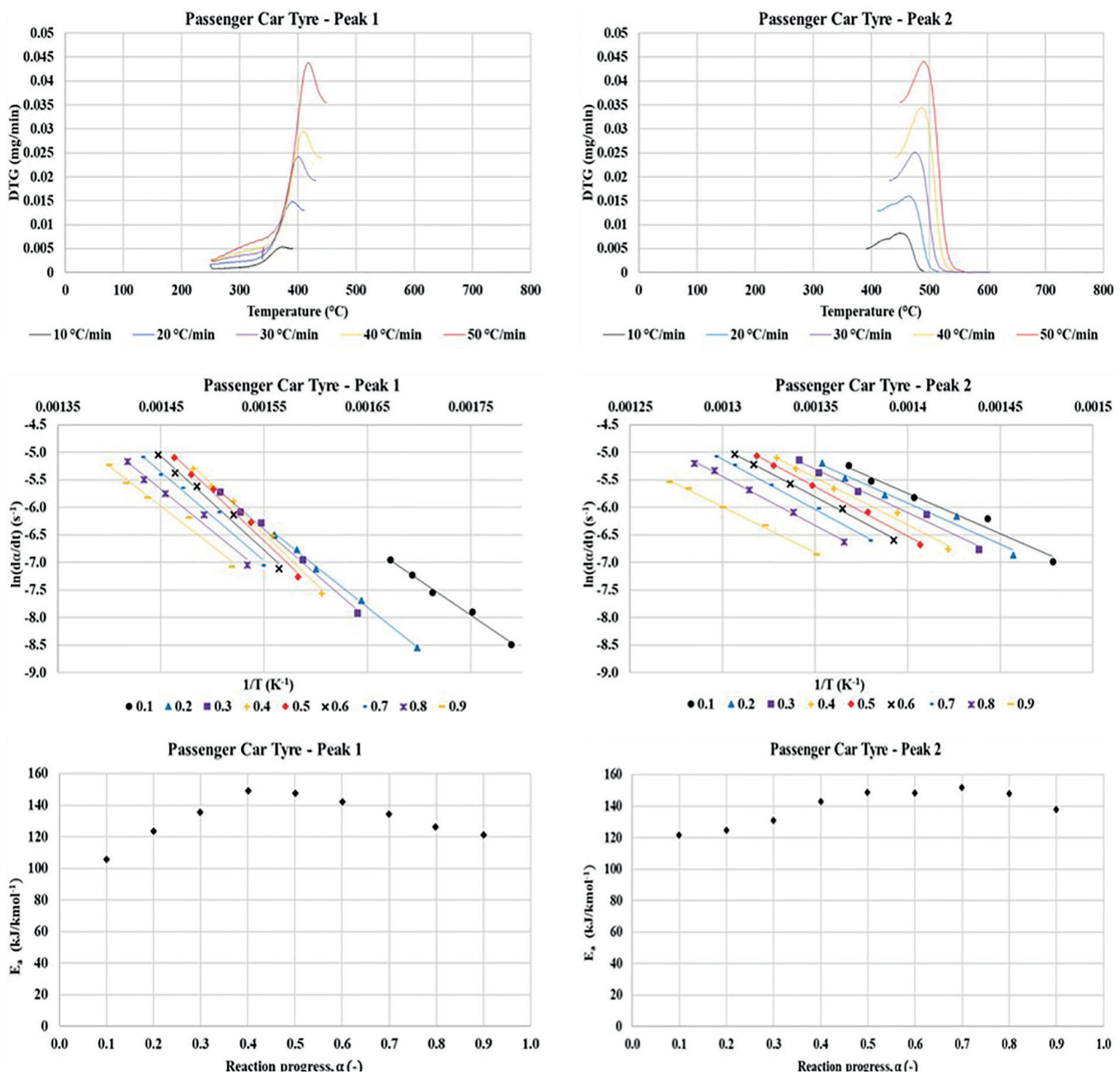

Passenger Car Tyre - Peak 1
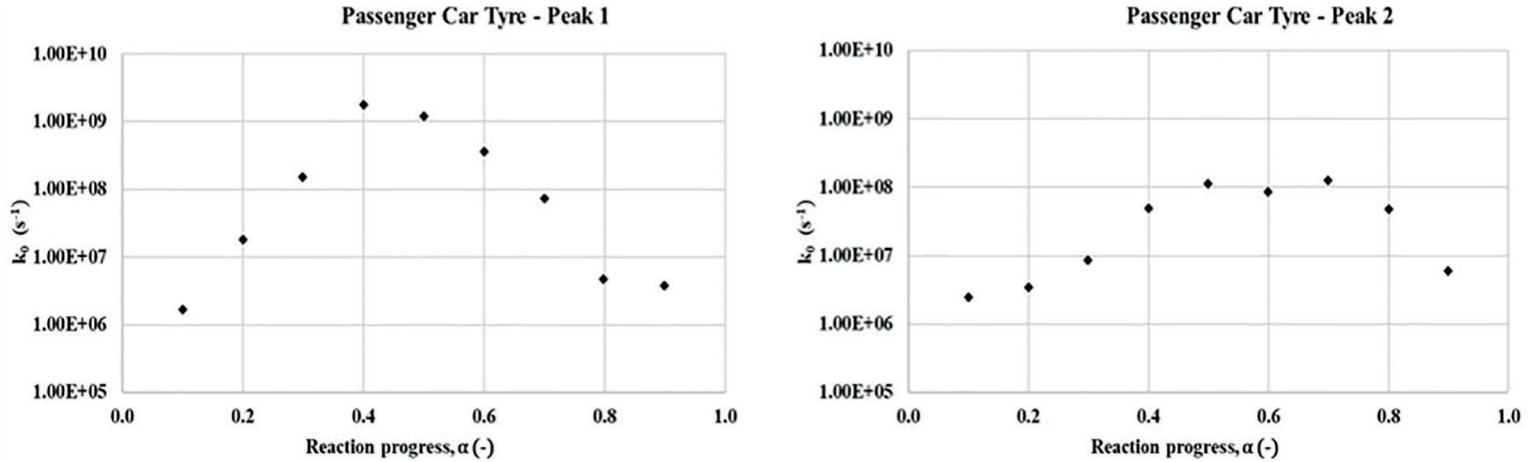

FIGURE 6: Fractional derivative thermograms and Iso-conversional Friedman analysis plots for the PCT.

\section{REFERENCES}

Antoniou, N., \& Zabaniotou, A. (2013). Features of an efficient and environmentally attractive used tyres pyrolysis with energy and material recovery. Renewable and Sustainable Energy Reviews, 20, 539-558. https://doi.org/10.1016/j.rser.2012.12.005

Aylón, E., Callén, M. S., López, J. M., Mastral, A. M., Murillo, R., Navarro, M. V., \& Stelmach, S. (2005). Assessment of tire devolatilization kinetics. Journal of Analytical and Applied Pyrolysis, 74(1-2), 259-264. https://doi.org/10.1016/J.JAAP.2004.09.006
Banar, M., Akyildiz, V., Özkan, A., Çokaygil, Z., \& Onay, Ö. (2012). Characterization of pyrolytic oil obtained from pyrolysis of TDF (Tire Derived Fuel). Energy Conversion and Management, 62, 22-30. https://doi.org/10.1016/j.enconman.2012.03.019

Barlaz, M. A., Eleazer, W. E., \& Whittle, D. J. (1993). Potential To Use Waste Tires As Supplemental Fuel In Pulp And Paper Mill Boilers, Cement Kilns And In Road Pavement. Waste Management and Research, 11, 463-480. https://doi.org/10.1006/wmre. 1993.1050 
Chen, J. H., Chen, K. S., \& Tong, L. Y. (2001). On the pyrolysis kinetics of scrap automotive tires. Journal of Hazardous Materials, 84(1), 43-55. https://doi.org/10.1016/S0304-3894(01)00180-7

Cheung, K. Y., Lee, K. L., Lam, K. L., Chan, T. Y., Lee, C. W., \& Hui, C. W. (2011). Operation strategy for multi-stage pyrolysis. Journal of Analytical and Applied Pyrolysis, 91, 165-182. https://doi. org/10.1016/j.jaap.2011.02.004

Cheung, K. Y., Lee, K. L., Lam, K. L., Lee, C. W., \& Hui, C. W. (2011). Integrated kinetics and heat flow modelling to optimise waste tyre pyrolysis at different heating rates. Fuel Processing Technology, 92(5), 856-863. https://doi.org/10.1016/j.fuproc.2010.11.028

Conesa, J. ., Font, R., \& Marcilla, A. (1997). Mass spectrometry validation of a kinetic model for the thermal decomposition of tyre wastes. Journal of Analytical and Applied Pyrolysis, 43(1), 83-96. https://doi.org/10.1016/S0165-2370(97)00057-0

Danon, B., \& Görgens, J. (2015). Determining rubber composition of waste tyres using devolatilisation kinetics. Thermochimica Acta, 621, 56-60. https://doi.org/10.1016/j.tca.2015.10.008

Danon, B., Mkhize, N. M., Van Der Gryp, P., \& Görgens, J. F. (2015a). Combined model-free and model-based devolatilisation kinetics of tyre rubbers. Thermochimica Acta, 601, 45-53. https://doi. org/10.1016/j.tca.2014.12.003

Friedman, H. L. (1964). Kinetics of thermal degradation of char-forming plastics from thermogravimetry. Application to a phenolic plastic. Journal of Polymer Science Part C: Symposia, 4, 183-195.

Giugliano, M. M., Cernuschi, S., Ghezzi, U., Grosso, M., \& Giugliano, M. M. (1999). Evaluation of Waste Tires Utilization in Cement Kilns Experimental Evaluation of Waste Tires Utilization in Cement Kilns. Journal of the Air \& Waste Management Association Journal of the Air \& Waste Management Association J. Air \& Waste Manage. Assoc, 4912(49), 1405-1414. https://doi.org/10.1080/10473289.1999. 10463976doi.org/10.1080/10473289.1999.10463976

Kim, Seung; Park, Jae K.; Chun, H.-D. (1995). Pyrolysis kinetics of scrap tire rubbers. 1: Using DTG and TGA. Journal of Environmental Engineering, 121(7), 507-514. Retrieved from https://doi.org/10.1061/ (ASCE)0733-9372(1995)121:7(507)

Kissinger, H. E. (1957). Reaction kinetics in differential analysis. Analytical Chemistry, 27, 1702-1706.

Lah, B., Klinar, D., \& Likozar, B. (2013). Pyrolysis of natural, butadiene, styrene-butadiene rubber and tyre components: Modelling kinetics and transport phenomena at different heating rates and formulations. Chemical Engineering Science, 87, 1-13. https://doi. org/10.1016/J.CES.2012.10.003

Lam, K.-L., Lee, C.-W., \& Hui, C.-W. (2010). Multi-stage Waste Tyre Pyrolysis: An Optimisation Approach. Chemical Engineering Transactions, 21(21), 853-858. https://doi.org/10.3303/CET1021143

Leung, D. Y. C., \& Wang, C L.. (1999). Kinetic Modeling of Scrap Tire Pyrolysis. Energy and Fuels, 13(2), 421-427. https://doi.org/10.1021/ ef980124l
Lopez, G., Aguado, R., Olazar, M., Arabiourrutia, M., \& Bilbao, J. (2009). Kinetics of scrap tyre pyrolysis under vacuum conditions. Waste Management, 29(10), 2649-2655. https://doi.org/10.1016/j.wasman.2009.06.005

Lopez, G., Olazar, M., Amutio, M., Aguado, R., \& Bilbao, J. (2009). Influence of tire formulation on the products of continuous pyrolysis in a conical spouted bed reactor. Energy and Fuels, 23(11), 54235431. https://doi.org/10.1021/ef900582k

Mkhize, N. M., van der Gryp, P., Danon, B., \& Görgens, J. F. (2016). Effect of temperature and heating rate on limonene production from waste tyre pyrolysis. Journal of Analytical and Applied Pyrolysis, 120, 314-320. https://doi.org/10.1016/j.jaap.2016.04.019

Mui, E. L. K., Ko, D. C. K., \& McKay, G. (2004). Production of active carbons from waste tyres--a review. Carbon, 42(14), 2789-2805. https://doi.org/10.1016/J.CARBON.2004.06.023

Mui, E. L. K., Lee, V. K. C., Cheung, W. H., \& McKay, G. (2008). Kinetic Modeling of Waste Tire Carbonization. Energy and Fuels, 22(3), 1650-1657. https://doi.org/10.1021/ef700601g

Olazar, M., Aguado, R., Vélez, D., Arabiourrutia, M., \& Bilbao, J. (2005). Kinetics of scrap tire pyrolysis in a conical spouted bed reactor. Industrial and Engineering Chemistry Research, 81, 127-132. https://doi.org/10.1021/ie040259g

Quek, A., \& Balasubramanian, R. (2012). Mathematical modeling of rubber tire pyrolysis. Journal of Analytical and Applied Pyrolysis, 95, 1. https://doi.org/10.1016/j.jaap.2012.01.012

Quek, A., \& Balasubramanian, R. (2013). Liquefaction of waste tires by pyrolysis for oil and chemicals - A review. Journal of Analytical and Applied Pyrolysis, 101, 1-16. https://doi.org/10.1016/j. jaap.2013.02.016

Seidelt, S., Müller-Hagedorn, M., \& Bockhorn, H. (2006). Description of tire pyrolysis by thermal degradation behaviour of main components. Journal of Analytical and Applied Pyrolysis, 75, 11-18. https://doi.org/10.1016/j.jaap.2005.03.002

Senneca, O., Salatino, P., \& Chirone, R. (1999). A fast heating-rate thermogravimetric study of the pyrolysis of scrap tyres. Fuel, 78(13), 1575-1581. https://doi.org/10.1016/S0016-2361(99)00087-3

Sienkiewicz, M., Kucinska-Lipka, J., Janik, H., \& Balas, A. (2012). Progress in used tyres management in the European Union: A review. Waste Management, 32, 1742-1751. https://doi.org/10.1016/j. wasman.2012.05.010

Williams, P. T. (2013). Pyrolysis of waste tyres: A review. Waste Management, 33, 1714-1728. https://doi.org/10.1016/j.wasman.2013.05.003

Zabaniotou, A., Madau, P., Oudenne, P. D., Jung, C. G., Delplancke, M. P. \& Fontana, A. (2004). Active carbon production from used tire in two-stage procedure: Industrial pyrolysis and bench scale activation with $\mathrm{H} 2 \mathrm{O}-\mathrm{CO} 2$ mixture. Journal of Analytical and Applied Pyrolysis, 72, 289-297. https://doi.org/10.1016/j.jaap.2004.08.002 